[Aus dem Institat für Hygiene und Bakteriologie zu Gelsenkirchen.]

(Leiter: Prof. Dr. Hayo Bruns.)

\title{
Vergleichende Untersuchungen über den diagnostischen Wert einiger neuerer Typhusnährböden.
}

Von

Dr. Wilhelm Studte,

Arzt.

Immer wieder erscheinen in der Literatur Mitteilungen über noue Typhusnährböden, und es liegt wohl darin der beste Beweis, daB es cinen Idealnährboden, der die bakteriologische Diagnose Typhus in der Mehrzahl der Fälle zu stellen gestattet, zurzeit noch nicht gibt. Ein solcher Nïhrboden soll einerseits den im Untersuchungsmaterial vorhandenen Typhusbazillen gute oder beste Existenzbedingungen schaffen, andererseits die Begleitbakterien, besonders Bact. coli, hemmen. Ferner sucht man auch möglichst einen Farbenunterschied zwischen den Kolonien der Typhusund denen der Begleitbakterien, besonders wieder Bact. coli, zu schaffen. Auch bei den von mir geprüften, dem Conradischen Brillantgrünagar (1), dem Werbitzkischen Chinagrünagar (2), dem Gaethgensschen KoffeinEndoagar (3), dem Kindborgschen Säurefuchsinagar (4) und dem Löfflerschen Reinblauagar (5) kommt das eine oder andere Prinzip oder auch beide zur Anwendung. Zum Vergleich benutzte ich den bewährten und anerkannten Endoschen Nährboden $(6,7,8,9)$, der im Gelsenkirchener Institut neben dem Conradi-Drigalskischen und früher noch Padlewskischen Nährboden vorwiegend zur Züchtung der Typhasbazillen aus Faeces und Urin benutzt wird. AuBer den von mir angelegten Endo- 
schen Platten hatte ich in jedem Falle auch noch die des Instituts zur Kontrolle, wo das betreffende Material gleichzeitig als laufende Untersuchung verarbeitet wurde. Der Zweck meiner Untersuchungen war der, daB ich an der Hand des dem oben bezeichneten Institut täglich eingehenden auf Typhus- oder Paratyphus zu untersuchenden Materials feststellen wollte, wieweit mit Hilfe der genannten Nährböden sich die Diagnose Typhus oder Paratyphus schnell und sicher stellen läBt. Es lag dabei nahe, die Erfolge meiner Untersuchungen über die genannten Nährböden mit denen anderer Untersucher zu vergleichen und diese Vergleiche dem Rahmen dieser Arbeit einzufügen.

Conradis Absicht war, die Begleitbakterien ohne irgend welche Schädigung der Typhusbakterien möglichst auszuschalten. Auf einen direkten Farbenkontrast zwischen Typhus- und Colibakterien verzichtete er. Dies ist der Gedanke der Conradischen Methode. Die Fähigkeit, die Typhusbazillen zu schonen und gegen Begleitbakterien eine antiseptische Wirkung zu entfalten, haben manche Anilinfarbstoffe. Die Auffindung und Erprobung solcher Anilinfarbstoffe lieB sich Conradi (10) schon früher angelegen sein. In dieser Zeitschrift schrieb er 1901, daB Malachitgrün und Brillantgrün in starker Verđünnung vermehrend auf Typhusbazillen einwirkten. Conradi prüfte allmählich 400 Farbstoffe systematisch durch und fand schlieBlich, daB Pikrinsäure (Trinitrophenol) und „Brillantgrün krist. extra rein" (Tetraäthyldiamidotriphenylkarbinolsulfat) der Höchster Farbwerke sich in ihrer antiseptischen Wirkung gegen Begleitbakterien am bèsten bewährten. Pikrinsäure gebrauchte er in einer Verdünnung 1:15000, Brillantgrün 1:150000 bei einem Säuregrad des Agars von 3 Prozent. Nach Conradis Vorschrift besteht 1 Liter seines Agars aus $900 \mathrm{~cm}$ Wasser, $30 \mathrm{grm}$ Fadenagar, $20 \mathrm{grm}$ Liebigs Fleischextrakt, $100 \mathrm{~cm}$ einer 10 prozentigen wässerigen Witteschen Peptonlösung. Der Zusatz der filtrierten und sterilisierten Peptonlösung erfolgt erst, nachdem die Sterilisierung des Agars und seine Filtration durch Watte beendet ist. Dann wird die Reaktion des Peptonfleischextraktagars hergestellt und so viel Normalnatronlauge bzw. Normalphosphorsäure zugefügt, daB vom Phenolphtaleinneutralpunkt ab der Säuregrad 3 Prozent beträgt, d. h. zur Neutralisierung von $100^{\mathrm{ccm}}$ Agar gegen Phenolphtalein $3^{\mathrm{ccm}}$ Normalnatronlauge erforderlich sind. Hierauf kommen $\mathrm{zu} 1 \frac{1}{2}$ Liter Agar je $10^{\mathrm{cm}}$ einer 1 promill. wässerigen Lösung von ,Brillantgrün krist. extra rein" (Höchst) und einer 1 prozent. wässerigen Lösung von Pikrinsäure (Dr. Grübler-Leipzig). Nach Durchmischung wird der hellgrüne klare Agar in große Doppelschalen ausgegossen. Nach Conradis Vorschrift genügt es, auf einer, höchstens zwei Platten, mittels Glasspatels so viel Material auszusåen, als ob drei grobe Drigalski-Conradiplatten zur Ver- 
fügung ständen. Nach 18 bis 20 stündigem Verweilen im Brutschrank $\left(37^{\circ}\right)$ sollen die Typhuskolonien typisches Wachstum haben, und zwar sollen sie als 2 bis $3^{\mathrm{mm}}$ große glattrandige Kolonien wachsen, die hellgrün, durchsichtig, rundlich, flach und in der Mitte dicker als am hande sind. Mit der Lupe soll eine körnige Struktur, besonders anu' dunklem Hintergrunde erkennbar sein. Bact. paratyphi wächst nach l'unradis Augabe etwas größer, üppiger, geht mehr ins Gelbgrüne über, bildet häufig Riesenkolonien und Rasen, die durchsichtig, von spiegelnder Oberlliche sind, Randbuchten zeigen und denen fein gezackte Ränder fehlen. Bact. coli soll so gut wie ausgeschaltet sein, höchstens noch Pyocyancus, einige Alkaligenes- bzw. Proteusarten wachsen. Conradi fand auf diesem Nährboden bei Untersuchung von 2850 Faeces in der Neuenkirchener Anstalt 325 mal Typhus, 35 mal Paratyphus, bei Untersuchung von 2515 lirinen 105 mal Typhus, 26 mal Paratyphus.

Werbitzki (2) untersuchte eine Reihe von Farbstoffen dur Bayerschen Farbwerke auf ihre Anwendbarkeit für den Nachweis von Typhussbazillen in Faeces und fand dabei einen Farbstoff, Chinagrün, der in dieser Hirisicht allen bis jetzt vorgeschlagenen Stoffen überlegen sein sullte. Durch Vorversuche stellte er fest, daB Chinagrün in einer Konzentrution von 1:41000 bis 1:38000 bei einem Agar von 1.3 Prozent Normalnatronlauge unter dem Phenolphtaleinneutralpunkte am günstigstın \%u verwenden sei. Bei fast vollständiger Hemmung des Wachstums der Colibakterien betrug die Ernte der Typhusbazillen fast die Hälfte der Aussaat (47 Prozent). Von 9 künstlich infizierten Faeces hatte Worbit\%ki 7 positive, 2 negative Resultate. Bei einigen echten Typhusfueces hatte er auch gute Resultate. Werbitzki legte 2 Platten bei seinen Versuchen an, die er nach 20 stündigem Verweilen im Brutschrank bei $3^{\circ}$ abschwemmte. Er ging also wie beim Lentz-Tietz-Verfahren (11) vor. Versuche nämlich, so schreibt er selber, charakteristische \%uverlïssige Merkmale der Typhuskolonien auf dem Chinagrünagar zu finden, die sie direkt vom Chinagrünagar zu isolieren gestatteten, sind ergebnislos geblieben. Das Chinagrün teilt nach Werbitzkis Erfahrung die Eigenschaft, daß verschiedene Typhusstämme sich verschieden empiindlich dagegen verhalten, wie dies vom Malachitgrün ebenfalls bekaunt ist $(12,13,14)$. Am empfindlichsten waren alte Laboratoriumsstämme. Viel stärker empfindlich war Bact. coli. Sterilisieren verträgt Chinagrün ebenfalls nicht. Die auffallende Begünstigung der Typhusbazillen und die starke Hemmung der Begleitbakterien aber sollte das Chinagrün zu einem für den Nachweis von Typhusbazillen ganz besonders geeigneten Farbstoff machen. Werbitzkis Methode zur Herstellung seines Agars war folgende: $500 \mathrm{grm}$ mageres Rindfleisch werden mit 1 liter Wasser versetzt und verrührt, 
unter Umrühren $3 / 4$ Stunden gekocht, der Verlust durch Wasserzugabe ersetzt, das Fleischwasser dann durch ein Koliertuch gegeben, die Kolatur im MeBzylinder gemessen, mit 1 Prozent Peptonum siccum Witte und 0.5 grm Kochsalz versetzt. Dann wird das Gemisch zum Sieden gebracht, im kalten Bad abgekühlt, durch FlieBpapier filtriert, das Filtrat mit 3 Prozent Agar versetzt, bis zur Lösung im Dampftopf gehalten, dann mit Normalnatronlauge neutralisiert. Die Reaktion soll einem Gehalt von 1.3 Prożent Normalnatronlauge unter dem Phenolphtaleinneutralpunkt entsprechen. Dann wird die Lösung im Kochschen Dampftopfe filtriert, auf Erlenmeyersche Kölbchen zu $100 \mathrm{~cm}$ abgefüllt und sterilisiert. Direkt vor dem Gebrauch werden zu $100 \mathrm{~cm}$ verflüssigtem, dann *auf 65 bis $60^{\circ}$ abgekühltem Agar 1.4 bis $1.5^{\mathrm{cm}}$ einer 0.2 prozent. Chinagrünlösung zugefügt. Zur Aussaat werden die Faeces mit 0.85 prozent. Kochsalzlösung aufgeschwemmt und zu dünnflüssigem Brei verrieben. Von diesem Brei werden je $0 \cdot 1$ bis $0.3^{\mathrm{cm}}$ auf zwei große Doppelschalen mit dem Glasspatel ausgestrichen. Dann kommen die Platten 20 Stunden bei $37^{\circ}$ in den Brutschrank, werden danach mit 8 bis $10^{\mathrm{ccm}}$ physiologischer Kochsalzlösung abgeschwemmt, und von der obersten Schicht der Abschwemmung werden 1 bis 3 Osen auf eine Drigalski-ConradiPlattenserie (zu 2 Platten) übertragen und mittels Glasspatel verrieben.

Der dritte der von mir untersuchten Nährböden, Gaethgens' KoffeinEndofuchsinagar (3) ist eigentlich nur der alte Endosche Nährboden, dem Gaethgens Koffein zwecks Anreicherung der Typhusbazillen und Hemmung der Begleitbakterien zusetzte. Die Fähigkeit des Koffeins, anreichernd auf Typhusbakterien und hemmend auf Begleitbakterien zu wirken, wurde von Roth (15) im Jahre 1903 entdeckt, in demselben Jahre, in dem Löffler (16) das Malachitgrün in die Technik der bakteriologischen Typhusuntersuchung einführte. Das Koffein hielt aber nicht, was es anfangs versprach, und nur ein darauf beruhendes Verfahren, das von Ficker und Hoffmann (17) bewährte sich, erwies sich aber als zu umständlich, um allgemein eingeführt zu werden. Gaethgens nahm die Versuche mit Koffein wieder auf. Er wollte durch Zusatz eines colihemmenden Mittels zum gewöhnlichen Endo- bzw. Drigalskiagar einen Nährboden schaffen, der einfach auszuführen und von derselben Leistungsfähigkeit war wie in Klingers Versuchen (18) das Anreicherungsverfahren F i cker-Hof fmann (17) mit 58.9 Prozent oder die Vorkultur auf. Malachitgrün mit 68.6 Prozent positiven Fällen. Das Optimum des Koffeinzusatzes fand Gaethgens zwischen 0.32 und 0.34 Prozent bei einer Allalinität des Nährbodens von 1.5 Prozent unter dem Phenolphtaleinneutralpunkte. Bald zeigte sich aber in Gaethgens' Versuchen, daB die Typhusbakterien auf den neuen Platten nicht so schnell wuchsen 
als auf den gewöhnlichen Endoschen, das Koffein wirkte verlangsamend auf das Wachstum, und in bezug auf schnelle Diagnosenstellung versagte also der Nährboden. Bact. coli aber wurde so stark gehemmt, daB nur vereinzelte Keime zur Fntwicklung gelangten. Nach 30 stündigem Verweilen im Brutschrank bei $37^{\circ}$ bildeten sich kümmerlich entwickelte, rot gefärbte Kolonien von 1 bis 2 mm Durchmesser mit zackigen Ausläufern. Die Typhuskolonien erschienen, so schreibt Gaethgens, nach 28- bis 30 stündigem Aufenthalt im Brutschrank $\left(37^{\circ}\right)$ als 2 bis $3^{\mathrm{mm}}$ groBe, scharf und deutlich rom schwach rötlich scheinenden Nährsubstrat sich abhebende Kolonien, von runder platter Form mit feinen zackigen Ausläufern, die im durchfallenden Lichte total farblos, im auffallenden schwach rosa waren. Eine Reihe von Bakterien, die auf Endos Nährboden typhusähnlich wachsen und leicht zu Täuschung AnlaB geben, unterschieden sich auf dem Gaethgensschen in Form und Aussehen wesentlich von Typhuskeimen. Die einzelnen Typhusbazillen waren, wie Gaethgens fand, zu Fäden ausgewachsen, von geringerer Beweglichkeit als erstere. Es entstanden bei der Agglutination wirr verschiungene Fäden. Immerhin fand Gaethgens diese Agglutination doch so charalteristisch, und sie erfolgte so regelmäßig, daß nach seiner Ansicht bei einiger Übung schon daraufhin die bakteriologische Diagnose Typhus gestellt werden könnte. Die Erschwerung der Agglutination durch Koffein war übrigens bekannt und wurde schon von Reischauer (19) als zu tadelnde Eigenschaft dieses Stoffes hervorgehoben. Die Methode der Herstellung des Nährbodens war folgende: 2 Liter Leitungswasser, $20 \mathrm{grm}$ Liebigs Fleischextrakt, 20 grm Witte-Pepton, 10 grm Kochsalz, $80^{\mathrm{grm}}$ Stangenagar werden zusammen 2 Stunden bei $110^{\circ}$ im Autoklaven gekocht. Nachdem völlige Lösung des Agars eingetreten war, wird einmal durch Watte filtriert. $\mathrm{Zu}$ diesem Gemisch werden $20 \mathrm{grm}$ Milchzucker, $10^{\mathrm{cem}}$ einer 10 prozent. alkoholischen Fuchsinlösung und $10^{\mathrm{ecm}}$ einer Natriumsulitlösung (5 $\mathrm{grm}$ Natriumsulfit auf $50 \mathrm{~cm}$ Wasser) zugefügt, die F'lüssigkeit zu je $200 \mathrm{~cm}$ in Erlenmeyersche Kölbchen abgefüllt und im Iunkeln aufbewahrt. Vor dem Gebrauch wird der Agar im strömenden Dampfe gelöst, mit verschiedenen Mengen von Koffein (0.33 Prozent) und Normalnatronlauge (1.5 Prozent unter dem Phenolphtaleinneutralpunkt) versetzt and in flache Glasschalen von $20 \mathrm{~cm}$ Durchmesser ausgegossen. Gaethgens säte $0.5^{\mathrm{cm}}$ eines verdünnten Stuhles auf einer groBen Platte aus und ging mit demselben Glasspatel, mit dem auf der ersten Platte verrieben war, auf eine zweite Platte über. Eine dritte und vierte Platte hielt er nicht für erforderlich. Gleichzeitig legte er bei seinen Versuchen je zwei Endo- und je zwei Drigalskiplatten zum Vergleich an. Seine Versuche erstreckten sich im ganzen auf 168 Faeces, die von fiebernden 
Typhuskranken, Rekonvaleszenten und Bazillenträgern stammten. Positiv auf dem Koffein-Endofuchsinagar G a eth ge n s' waren 66 Prozent, auf Drigalskis Lackmusagar nur 37. Prozent und auf Endos Fuchsinagar nur 48 Prozent der Fälle. Die Versuche Gaethgens stellten eine zweifellose Überlegenheit des Koffeinnährbodens gegenüber dem gewöhnlichen Endoschen und dem Drigalskischen Lackmusmilchzuckeragar dar und kamen fast dem Malachitgrün-Vorkulturverfahren in Klingers (18) Versuchen gleich. Auch Bact. paratyphi wuchs gut auf den Gaethgensschen Platten. In Gaethgens Untersuchungen ließen sich zweimal Paratyphusbakterien nachweisen in Fällen, wo einfacher Endo einmal, Conradi-Drigalskiagar zweimal versagt hatte.

Dem vierten von mir nachgeprüften Nährboden, von E. und A. Kindborg (4) angegeben, liegt der Gedanke zugrunde, den Typhusbacillus, nicht wie bisher das Bact. coli, durch eine Farbenreaktion kenntlich zu machen. Als koloristisches Mittel verwendeten sie Säurefuchsin, „Fuchsin S“. Das Bact. typhi vermag Nitrite aus den im Fleischwasseragar reichlich vorhandenen Nitraten zu bilden. Die Nitrite entfärben das „Fuchsin S", und die Typhuskolonien sollten so als helle Punkte auf dem dunkelroten Nährboden erscheinen. Da nun auch Bact. coli und Proteus Nitrite bilden (20), also auch von diesen Bakterien Entfärbung des Nährbodens zu erwarten war, so setzten E. und A. Kindborg dem Nährboden Milchzucker zu, der bekanntlich von Säurebildnern wie Bact. coli usw. vergoren wird. Die entstandene Säure bildet nach Kindborgs Ansicht aus dem farblos gemachten „Fuchsin $S^{* 6}$ einen neuen roten Farbstoff, so daB Colibakterien als rote Kolonien wachsen. Um neben Bact. typhi andere Nitritbildner überhaupt möglichst auszuschließen, verwendeten E. und A. Kindborg ein für Bact. typhi relativ unschädliches, andere Bakterien hemmendes Mittel, nämlich Malachitgrün. Kindborgs entdeckten nun, daß auch Malachitgrün durch Nitrite entfärbt, daß also die Typhuskolonien trotz Malachitgrünzusatz entfärbt wurden, und dabei wurde gleichzeitig auf Begleitbakterien ein hemmender Einfluß ausgeübt. Das von E. und A. Kindborg verwendete Malachitgrün war von Dr. Grübler-Leipzig bezogen und als ,Malachitgrün Höchst, Fabrikmarke Ia" bezeichnet. Kindborgs raten aber bei der Verwendung des Malachitgrüns zu einer gewissen Vorsicht. Eine Grenze der Verdünnung desselben, die Bact. typhi unbeschädigt lieB, andere Keime aber hemmte, fanden sie nicht, und sie schlieben sich der Ansicht Lubenaus (21) an, welcher behauptet, das Malachitgrün wäre in den üblichen Verdünnungen kein indifferenter Stoff für Typhusbakterien, und sie schlieBen sich auch den übereinstimmenden Beobachtungen Neumanns (22), Doeberts (13) und Nowacks (14) an, denen zufolge die einzelnen Typhusstämme ver- 
schieden empfindlich sind. Auch die Malachitgrünpräparate schwanken offenbar in ihrer Zusammensetzung, denn Jorus (23) fand in seinen Versuchen ganz andere Werte noch wirksamer Verdünnungen des Malachitgrüns $(1: 10000)$ als andere Untersucher. L. u. $\Lambda$. Kindborg raten daher jedem, der ihren Nährboden nachprüfen will, das Malachitgrün in der gewohnten Stärke oder besser noch etwas geringer zuzusetzen. Zu demselben SchluB kommen auch Peabody und Pratt (24) in einer Arbeit über den Wert von Malachitgrünnährböden. In l'ällen, wo bei einer ersten Untersuchung keine Typhusbakterien gefunden werden, es sich also um einige wenige geschwächte Typhusbazillenexemplare handeln muB, raten E. u. A. Kindborg das Malachitgrün überhaupt worzulussen. Ich verwendete aber stets Malachitgrünzusatz, da ich ein eventuelles Variieren der Herstellung des Nährbodens für einen erschwerenden Úmstand halte, dem von seiten des Laboratoriumsgehilfen im (iroblutriebe wenigstens nicht immer Rechnung getragen werden kann. I)in! Renktion des Nährbodens ist nach E. u. A. Kindborgs Erfahrungen von grobem EinfluB auf die Wirksamkeit des Malachitgrüns. Nach ihrer Ansioht handelt es sich um eine Alkalinitätsschwelle, die nicht überschritten werden darf. Der Kindborgsche Nährboden wird folgendermaben hergestellt: Ein neutraler 3 prozent. Fleischwasseragar wird zu 200$)^{\cdots \cdots}-P_{o r}-$ tionen vorrätig gehalten. Zum Gebrauch erhitzt man, überzeugt sich, daB die Reaktion noch neutral ist, und alkalisiert erst jetzt, weil vorher die alkalische Reaktion beim Sterilisieren EinbuBe leidet. Hine 'Trüibung des Mediums ist belanglos. Der Alkaleszensgrad wird durch Zusut\% vou 0.75 prozent. Normalnatronlauge, nicht wie üblich Normalsodalïsung, nuch Einstellung auf Lackmusneutralität erreicht. Dann setzt man zum verflüssigten Agar 5 Prozent Milchzucker und erhitzt im Wasserbude, bis dieser vollständig gelöst ist. Zum Schluß setzt man das Sïurefuchsin, $5 \mathrm{~cm}$ einer gesättigten wässerigen Lösung, $\mathrm{zu} 100 \mathrm{~cm}$ Agrar und das Malachitgrün, $4^{\mathrm{cm}}$ einer Lösung $1: 120$, hinzu und gieBt in I)rigalskischalen aus. Die Platten sollen dann 24 Stunden in den Brutschrank gestellt werden, wo sich das Kondenswasser verliert. Die Aussaat solite mittels einer $15^{\mathrm{mm}}$ langen, $3^{\mathrm{mm}}$ breiten Schlinge erfolgen, weil der Nährboden für Verreibung mit dem Glasspatel nicht fest genug sei. Zwar fand ich letztere Behauptung bestätigt, verwandte aber trotzdem den gewohnten Spatel in meinen Untersuchungen, den ich leichter als sonst über den Nährboden bei der Aussaat führte, und vermied so das ZerreiBen des letzteren. Die Typhuskolonien sollten nach 18- bis 24 stündigem Verweilen im Brutschrank als helle Punkte in dunklem Grunde erscheinen, und nach 48 Stunden sollte die Entfärbung noch weiter fortgeschritten sein. E. u. A. Kindborg legten bei ihren Untersuchungen eine Platte an. 
Löffler (4), der im Jahre 1903 das Malachitgrün in die Technik der Typhusuntersuchung einführte, arbeitete im Laufe der Jahre bestimmte Methoden aus, die auf den Eigenschaften des Malachitgrüns beruhten (16). Aber alle diese Nährböden stellten noch lange nicht das Ideal eines zum kulturellen Nachweis von Typhusbakterien geeigneten Nährbodens dar. Durch Zusatz versehiedener Farbstoffe versuchte Löffler unter Beibehaltung seines Malachitgrünagars eine leichtere Differenzierung der Typhusbakterienkolonien von den Kolonien anderer Bakterien zu erreichen. Von allen Farbstoffen, die als Zusatz zu dem Malachitgrünagar geprüft wurden, erwiesen sich als am besten geeignet das "Safranin rein", von Dr. Grübler-Leipzig, und kombiniert mit diesem zunächst das Azoblau, Farbstoffe, die sich früher für die Entwickiung der Typhusbakterien in gefärbten Nährsubstraten als besonders geeignet gęeigt hatten. Bei weiteren Versuchen, den Unterschied zwischen Bact. typhi und Bact. coli noch deutlicher zu machen, versagte das Azoblau und wurde durch einen von den Höchster Farbwerken bezogenen Farbstoff, „Reinblau doppelt konzentriert", ein Kalksalz der Diphenylrosanilinsulfosäure, ersetzt. Die Versuche mit dem Reinblau fielen sehr günstig aus, die Typhuskolonien nahmen eine intensiv blaue Farbe an. Die Kombination dieses Farbstoffes mit einem Malachitgrünnährboden hält nun Löffler für sehr günstig, weil auf letzterem durch das Nichtgedeihen zahlloser Colikolonien die Chancen der Entwicklung der Typhuskeime sich wesentlich verbessern sollen. Die praktische Erfahrung, schreibt Löffler, hat ergeben, daB es mit dem malachitgrünhaltigen Agar sehr viel leichter gelingt, die Typhuskeime nachzuweisen als mit solchen Agararten, die ein ungehindertes Wachstum aller Keime gestatten. Als weiteren, die Typhuskeime begünstigenden Zusatz verwendete Löffler sterile Rindergalle. Die Entscheidung darüber, ob dieser Gallenzusatz wirklich wachstumsfördernd auf die Typhusbazillen wirkt oder ob er fortgelassen werden kann, überläßt Löffler noch weiteren auszuführenden Versuchen. Sehr wichtig ist nach Löfflers Angabe eine genaue Befolgung der Vorschrift zur Herstellung des Nährbodens: $21 / 2$ Pfund Rindfleisch werden zerkleinert, mit 5 Litern Wasser angesetzt, 1 Stunde im Aluminiumkessel gekocht, filtriert, das Filtrat auf 5 Liter anfgefüllt. Diese 5 Liter Bouillon werden mit 150 grm feinstem 3 prozent. Stangenagar bis zur Lösung des Agars gekocht. Dann wird mit gesättigter Natriumkarbonatlösung unter Tüpfeln auf empfindlichem Lackmuspapier neutralisiert. Es wird so lange Natriumkarbonatlösung zugesetzt, bis blaues Lackmuspapjer dunkelviolett erscheint; rotes Lackmuspapier wird alsdann schwach gebläut. Darauf werden noch $25 \mathrm{~cm}$ Normalsodalösung zugegeben. Nach dem Neutralisieren wird nochmals aufgekocht, und zu der heißen Flüssigkeit werden $50 \mathrm{grm}$ Nutrose, die in 
$500^{\mathrm{cem}}$ etwa $70^{\circ}$ warmen Wassers langsam eingequirlt warden, hinzugesetzt. Jetzt wird die Gesamtmasse im Aluminiumtopf mehrmals durchgekocht und auf $1 / 2$ Literflaschen aus Jenenser Glas uufgefüllt. Auderes Glas verändert den Alkalinitätsgrad des Agars. In den Flusohen wird der Agar an zwei aufeinanderfolgenden Tagen je 2 Stunden im Dampfstrom gekocht, nach dem Flüssigwerden jedesmal tüchtig durchgeschüttelt, und im Dampfzylinder läßt man ihn erkalten. Es bildet sich oin Bodensatz, über dem ein klarer Agar steht. Der Agar muß einen hellen, gelblichweißen Farbenton haben, er darf beim Kochen nicht braun geworden sein. Ist dies der Fall, so war der Alkalizusatz zu hoch. Zum Gebrauch erfolgt Flüssigmachen des Agars in den Flaschen durch livehen

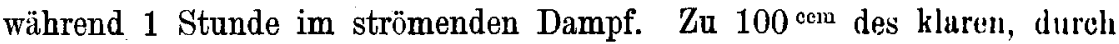
einfaches AbgieBen gewonnenen flüssigen Agars werden, nachdem er auf $45^{\circ}$ abgekühlt ist, hinzugefügt: $3^{\mathrm{ccm}}$ Galle, $1 \mathrm{~cm} 0.2$ Prozent Siafrunin, $3^{\mathrm{cem}} 1$ Prozent Reinblau, 4 bzw. $3^{\text {ocm }} 0.2$ Prozent Malachitgrïnlisung. Das verwendete Malachitgrün war „Malachitgrün-Chlorzinkdoppelsalz, Kristalle chem. rein". Nach guter Durchmischung wird in Petrischulen in $3^{\mathrm{mm}}$ dicker Schicht ausgegossen. Im durchfallenden Lichte sollen die Platten blauviolett aussehen. Ausgesät werden nach Löfflers Vorschrift auf einer Serie zu drei Platten ein Tropfen aus einer Glaskapillare oder zwei Platinösen des mit physiologischer Kochsalzlösung verdünnten Stuhles, von Urin 1 Tropfen auf einer Serie zu zwei Platten. Das Buct. typhi soll in Form blau durchscheinender flachpyramidaler Kolonien wachsen, mit unebener Oberfläche, nach mehr als 24 Stunden Bebrütung von deutlichem Metallglanz, während Bact. coli rot oder rötlich im durchfallenden Lichte erscheinen soll. Als Annehmlichkeit hebt Löffler hervor, daB der Agar kurzes Aufkochen im Dampftopf, selbst mehrmaliges Sterilisieren verträgt. Er rät jedoch, den Agar vor der Verwendung immer frisch mit Zusätzen zu versehen, weil sich sonst am Boden des in Platten ausgegossenen Agars kleinste, bei durchfallendem Lichte blau erscheinende Teilchen niederschlagen, eine Beobachtung, die ich nur bestätigen kann.

Bei der Herstellung der Nährböden hielt ich mich möglichst streng an die angegebenen Vorschriften, nur befolgte ich die mehrfach angegebene Vorschrift, durch FlieBpapier zu filtrieren, nicht, sondern filtrierte durch Watte. Das Verfahren ist viel schneller als die Filtration durch FlieBpapier, und der Agar wird ebenfalls vollständig klar. Alle bei diesen Versuchen verwendeten Farbstoffe waren aus der Fabrik von Dr. GrüblerLeipzig bezogen. Zunächst unternahm ich einige Vorversuche, um zu prüfen, ob die Nährböden richtig hergestellt wären, ob also überhaupt Wachstum darauf stattfände. Zu dem Zwecke stellte ich mir aus Typhus-, Paratyphus- bzw. Colibakterienreinkulturen durch Aufschwemmung je eine 
Verdünnung her, derart, daB in $1^{\mathrm{c}} \mathrm{cm}$ physiologischer Kochsalzlösung der betreffenden Verdünnung 100 Keime einer Bakterienart enthalten waren. Von dieser Verdünnung impfte ich auf je eine Conradi-WerbitzkiGaethgens-Kindborg-Plattenserie, jede zu zwei Platten, je zwei Ösen. Auf einer dritten Plattenserie, ebenfalls zu zwei Platten, säte ich gemischt aus, indem ich je eine Öse der Typhus- bzw. Paratyphusbakterienaufschwemmung und je eine Ose der Colianfschwemmung auf die Platte brachte. Im letzteren Falle konnte ich also das Wachstum von Typhusbzw. Paratyphus- und Colibakterien nebeneinander beobachten.

Vom Löfflerschen Nährboden legte ich in derselben Weise Serien (zu drei Platten) an, säte aber, da hierfür kleine Platten verwendet werden, nur je eine Öse jeder Aufschwemmung aus. Da ich mit meinen Versuchen hauptsächlich feststellen wollte, wieweit sich die zu prüfenden Nährböden zur schnellen und sicheren bakteriologischen Diagnostik eigneten, so hielt ich mich auch in den Vorversuchen nicht mit der Keimzahlbestimmung der aus den ausgesäten Keimen erzielten Ernte auf, sondern begnügte mich damit zu konstatieren, ob das Wachstum ein reichliches oder spärliches und charakteristisches war. Die Vorversuche ergaben, da $B$ auf keiner der Agarsorten eine wesentliche Hemmung der Typhusbakterien eintrat, nur auf den Gaethgensschen Platten wurde das Wachstum stark verlangsamt, und ferner ergab sich, da $B$ die Typhusbakterien im allgemeinen in der oben angegebenen charakteristischen Weise wuchsen; nur fand ich, daB auf dem Conradischen Nährboden die Typhuskolonien keine körnige Struktur zeigten, und auf dem Conradischen sowohl wie auf dem Werbitzki schèn Nährboden die Colibakterien entgegen meinen Erwartungen recht gut wuchsen. Auf dem Gaethgens schen Nährboden war die Wachstumsverlangsamung der Typhuskolonien so anBerordentlich, daß nach 30 stündigem Verweilen der Platten im Brutschrank bei $37^{\circ}$ die Kolonien erst als ganz feine, zarte Pünktchen von der Größe einer Stecknadelspitze erschienen. Die Hemmung des Bact. coli war allerdings eine vollständige. Erst nach 36 Stunden waren die Typhuskolonien von einiger Größe, so $\mathrm{daB}$ ein Weiterverarbeiten zur sicheren Diagnostik möglich war. Auf Kindborgs Säurefuchsinagar wuchsen die Typhuskolonien genau in der angegebenen Weise, d. h. als Kolonien mit heller Umgebung im dunklen Nährboden. Die Farbenreaktion trat aber nur ein, wenn der Nährboden in möglichst dünner Sehicht ausgegossen wurde, worauf ich denn in den Versuchen auch immer achtete. Bact. coli wuchs in den Vorversuchen fast gar nicht. Auf dem Löfflerschen Nährboden glaubte ich ein besseres Wachstum bei Zusatz von Galle konstatieren zu können. Die Typhuskolonien schienen mir heller, durchsichtiger und größer, so daß ich bei den Versuchen mit echten Typhusdejekten einen Gallenzusatz verwendete. 


\section{Zusammenstellung.}

\begin{tabular}{|c|c|c|c|c|c|c|c|c|c|c|c|}
\hline $\begin{array}{l}\dot{\vec{Z}} \\
\dot{\vec{Z}} \\
\dot{\overrightarrow{0}} \\
\end{array}$ & Klinische Augaben & 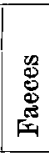 & $\stackrel{\nexists}{\vec{A}}$ & 赵 & 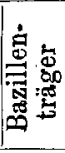 & 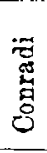 & 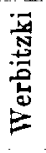 & 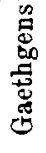 & 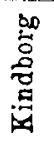 & 岕 & 总 \\
\hline 1 & & 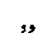 & & & " & - & - & - & - & - & - \\
\hline 2 & & و, & & & , & - & - & + & - & - & - \\
\hline 3 & & , & & & , & - & - & + & + & - & - \\
\hline 4 & & 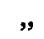 & & & , & - & - & - & - & - & - \\
\hline 5 & & , & & & , & + & + & - & - & + & + \\
\hline 6 & & " & & & ", & + & $t$ & - & - & - & + \\
\hline 7 & Typhusverdacht & " & & $"$ & & - & 一 & - & - & - & - \\
\hline 8 & & $"$ & & & , & - & - & - & - & -- & - \\
\hline 9 & $\begin{array}{l}\text { Typhusverdacht, } \\
\text { seit } 14 \text { Tagen Fieber }\end{array}$ & " & & , & & $\ldots$ & - & - & - & - & - \\
\hline 10 & & , & & & " & 一 & - & - & - & - & - \\
\hline 11 & & " & & & " & - & - & - & - & $\cdots$ & - \\
\hline 12 & Typhusverdaeht & $s$ & & "’ & & - & - & - & - & - & - \\
\hline 13 & & , & & & $"$ & + & + & - & - & + & + \\
\hline 14 & & " & & & $s$ & + & + & + & -- & - & + \\
\hline 15 & & , & & & " & - & + & - & - & + & + \\
\hline 16 & & , & & & , & + & + & + & + & + & - \\
\hline 17 & 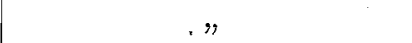 & $"$ & & $"$ & & - & - & - & + & - & + \\
\hline 18 & & , & & , & & + & - & - & + & & - \\
\hline 19 & Typhusverd., Durchfall, Fieber & , & & , & & - & 一 & - & - & - & - \\
\hline 20 & $"$ & , & & " & & - & - & - & - & - & - \\
\hline 21 & $"$ & " & & " & & + & - & + & - & + & - \\
\hline 22 & $"$ & ", & & " & & $\rightarrow$ & - & - & - & - & - \\
\hline 23 & & , & & , & & - & - & - & - & - & - \\
\hline 24 & $\begin{array}{l}\text { Typhusverdacht, Erbsbrei- } \\
\text { stühle, Ficker pos. }\end{array}$ & ", & • & ", & & - & 一 & - & - & + & - \\
\hline 25 & , & ", & & " & & 一 & - & + & - & - & - \\
\hline 26 & $\begin{array}{l}\text { 14 Tage krank, Mattigkeit, Milz- } \\
\text { sch wellg., Roseolen, kein Fieber }\end{array}$ & " & & " & & + & - & - & + & - & - \\
\hline 27 & Typhusverdacht, 14 Tage krank & " & & " & & - & - & - & - & - & - \\
\hline 28 & $\begin{array}{l}10 \text { Tage krank, ansteig. Fieber, } \\
\text { Milzschwellg., keine Durchfälle }\end{array}$ & " & & " & & - & - & - & - & + & - \\
\hline 29 & Typhusverd., seit 3 Woch. krank & & " & "g & & - & - & - & + & + & + \\
\hline 30 & Typhusverdacht. Widal positiv & & " & "s & & - & - & - & - & - & - \\
\hline 31 & Typhusverdacht & " & & " & & - & + & + & + & + & + \\
\hline 32 & $n$ & & $"$ & $\Rightarrow$ & & - & + & + & - & + & + \\
\hline 33 & seit 14 Tagen krank & $"$ & & $"$ & & - & - & - & - & - & - \\
\hline 34 & Typhusverdacht & $"$ & & $"$ & & - & - & - & - & - & - \\
\hline 35 & $" n$ & $"$ & & " & & - & - & - & - & - & - \\
\hline 36 & Früher Paratyphus & ” & & , & & - & - & - & - & - & - \\
\hline 37 & $"$ & " & & $"$ & & - & - & - & - & - & - \\
\hline 38 & $"$ & , & & " & & - & + & - & - & - & -1 \\
\hline
\end{tabular}

1 Paratyphus +. 
(Fortsetzung.)

\begin{tabular}{|c|c|c|c|c|c|c|c|c|c|c|c|}
\hline 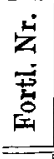 & Klinische Angaben & 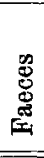 & 品 & 苨 & 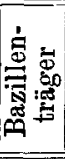 & 莺 & 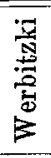 & 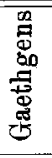 & 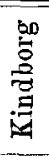 & 岁 & 욜 \\
\hline 39 & $\begin{array}{c}\text { Seit } 4 \%_{2} \text { Wochen krank, } \\
\text { letzte Untersuchung T.-B. pos. }\end{array}$ & " & & " & & - & - & - & - & - & - \\
\hline 40 & $\begin{array}{c}\text { Seit } 5 \text { Wochen krank, } \\
\text { letzte Untersuchung T.-B. pos. }\end{array}$ & " & & ," & & - & - & - & - & - & - \\
\hline 41 & $"$ & $"$ & & ", & & - & - & - & - & - & - \\
\hline 42 & Typhusverd., seit 9 Tagen krank & & ", & " & & - & - & - & - & - & - \\
\hline 43 & Pat.hat Yoghurtkur angefangen & $"$ & & & " & + & - & - & - & - & + \\
\hline 44 & & " & & & " & + & - & + & - & + & + \\
\hline 45 & Typhusverdacht & $"$ & & " & & + & + & + & + & - & + \\
\hline 46 & Seit 9 Wochen Yoghurtkur & $"$ & & & " & - & - & + & + & - & + \\
\hline 47 & Klinisch Typhus & " & & $"$ & & + & + & + & + & + & + \\
\hline 48 & Typhusverdacht & $"$ & & , & & - & - & - & - & - & - \\
\hline 49 & $"$ & & " & " & & - & - & - & - & - & - \\
\hline 50 & & $"$ & & & , & + & + & + & + & + & + \\
\hline 51 & & $"$ & & & , & + & 一 & + & + & + & + \\
\hline 52 & & " & & & , & + & - & + & + & - & + \\
\hline 53 & & " & & & " & + & - & + & + & - & + \\
\hline 54 & Typhusverdacht & " & & " & & - & - & - & - & - & - \\
\hline 55 & $"$ &, & & " & & - & - & - & - & 一 & - \\
\hline 56 & $"$ & ", & & , & & - & 一 & - & - & - & - \\
\hline 57 & $"$ & "s & & & $"$ & - & - & - & - & - & - \\
\hline 58 & Kliniseb Typhus & $"$ & & ", & & + & - & - & - & - & + \\
\hline 59 & & " & & & " & - & - & + & $\dot{r}$ & + & + \\
\hline 60 & Typhnsverdacht & ", & & $"$ & & + & + & + & + & + & + \\
\hline 61 & $\therefore$ & ", & & $"$ & & - & - & - & - & - & - \\
\hline 62 & Seit 9 Wochen Yoghurtkar & " & & & " & + & + & - & + & + & + \\
\hline 63 & Typhusverdacht &, & & ", & & - & - & - & - & - & 一 \\
\hline 64 & Klinisch Typhus & $"$ & & ", & & - & - & - & $\rightarrow$ & - & - \\
\hline 65 & Typhusverdacht & " & & , & & - & - & 一 & - & 一 & 一 \\
\hline 66 & $"$ & $"$ & & " & & - & - & - & - & - & - \\
\hline 67 & $\begin{array}{l}\text { Klinisch Typhus, seit } 5 \text { Woch. } \\
\text { krank, vor } 3 \text { Tagen pos. }\end{array}$ & 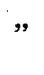 & & , & & - & - & - & - & - & - \\
\hline 68 & Klinisch Typhus, 8 Tage krank & $"$ & & $"$ & & - & - & + & - & + & + \\
\hline 69 & 8 Tage krank & & , & " & & - & - & - & - & - & - \\
\hline 70 & Klinisch Typhus, 8 Tage krank & $"$ & & " & & - & - & - & + & -- & - \\
\hline 71 & Klinisch Typhus & & ", & , & & - & - & - & - & - & - \\
\hline 72 & $"$ & $"$ & & , & & - & - & - & - & - & - \\
\hline 73 & $\eta$ & & " & " & & - & - & - & - & - & - \\
\hline 74 & $\begin{array}{l}5 \text { Tage krank, Durchfälle, } \\
\text { Schüttelfrost, Fieber }\end{array}$ & , & & ", & & - & - & - & + & - & - \\
\hline 75 & Urin von Nr. 74 & & ", & " & & - & - & 一 & - & - & - \\
\hline 76 & $\begin{array}{l}\text { Durchfälle, Ileocoecalgurren, } \\
\text { Milzschwellung, Roseolen, } \\
\text { hohes Fieber }\end{array}$ & ", & & $"$ & & + & - & + & - & - & - \\
\hline
\end{tabular}


(Fortsetzung.)

\begin{tabular}{|c|c|c|c|c|c|c|c|c|c|c|c|}
\hline 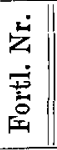 & Klinische Angaben & $\underbrace{0}_{0}$ & 寻 & 車 & 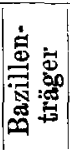 & 泀 & 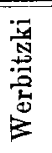 & 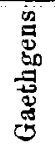 & 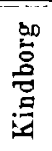 & 密 & 量 \\
\hline 77 & Typhusverdacht & " & & $"$ & & - & - & - & - & - & - \\
\hline 78 & Klinisch Typhus & $"$ & & $"$ & & - & - & - & + & - & - \\
\hline 79 & Typhusverdacht & $\eta$ & & & & - & - & - & $-\ldots$ & - & - \\
\hline 80 & $"$ & $"$ & & & & - & - & - & - & - & - \\
\hline 81 & Typhusverdacht, 8 Tage krank & $n$ & & $"$ & & - & - & + & + & - & + \\
\hline 82 & $"$ & $n$ & & $"$ & & - & - & - & - & - & - \\
\hline 83 & Urin von Fall 82 & & $n$ & $"$ & & 一 & 一 & - & - & - & - \\
\hline 84 & $\begin{array}{l}\text { Fieber, Benommenheit, } \\
\text { Milzschwellung }\end{array}$ & & $"$ & $"$ & & - & - & + & + & - & + \\
\hline 85 & & $"$ & & & $"$ & + & - & - & + & - & + \\
\hline 86 & Klinisch Typhus, Widal pos. & $"$ & & $"$ & & - & - & - & + & - & + \\
\hline 87 & 8 Tage krank, Magendarmkat. & $\Rightarrow$ & & $"$ & & 一 & - & - & - & - & +1 \\
\hline 88 & $\begin{array}{c}\text { Seit } 10 \text { Tagen hochfieberh. er- } \\
\text { krankt, mit } 3 \text { Familiengliedern } \\
\text { gleichzeitig }\end{array}$ & $"$ & & $\eta$ & & + & - & - & - & - & +1 \\
\hline 89 & Seit 6 Tagen krank, klin.Typhus & $"$ & & $"$ & & + & + & + & - & + & + \\
\hline 90 & $\begin{array}{l}8 \text { Tage krank, Kopfschmerz, } \\
\text { Müdigkeit, hohes Fieber, an- } \\
\text { geblich Vergiftung }\end{array}$ & " & & $"$ & & + & + & - & - & - & -1 \\
\hline 91 & $\begin{array}{l}\text { Hohes Fieber, MilzvergröBe- } \\
\text { rung, Durchfall, Roseolen }\end{array}$ & $"$ & & $"$ & & - & - & - & - & - & - \\
\hline 92 & Typhusverdacht & $"$ & & $"$ & & + & - & - & - & - & 一 \\
\hline 93 & Klinisch Typhus & $"$ & & $"$ & & - & - & - & - & - & - \\
\hline 94 & & $"$ & & " & & - & - & - & - & - & 一 \\
\hline 95 & $\begin{array}{l}\text { Klin. Typhus, letzte Unters. } \\
\text { Typhusbazillen pos., Widal pos. }\end{array}$ & $"$ & & $"$ & & - & - & - & - & - & - \\
\hline 96 & Klin. Typhus, 14 Tage krank & ", & & $n$ & & - & - & $\cdots$ & - & + & - \\
\hline 97 & Typhusverdacht & $"$ & & $"$ & & - & - & - & - & - & - \\
\hline 98 & $\begin{array}{c}\text { Klinisch Typhus, } 8 \text { Tage mit } \\
\text { Fieber erizrankt }\end{array}$ & $"$ & & $"$ & & - & - & - & - & - & - \\
\hline 99 & $\begin{array}{c}\text { Typhusverdacht, hohes Fieber, } \\
\text { Diarrhöen }\end{array}$ & $"$ & & $"$ & & - & - & - & - & - & - \\
\hline 00 & Urin von Fall 99 & & $"$ & $"$ & & - & - & - & - & - & - \\
\hline 101 & $\begin{array}{l}\text { Vor } 8 \text { Tagen Paratyphusbaz. } \\
\text { positiv, klin. Paratyphus }\end{array}$ & $"$. & & $"$ & & - & - & 一 & - & - & - \\
\hline 102 & Urin von Fall 101 & & $"$ & $"$ & & - & - & - & - & - & - \\
\hline 103 & $\begin{array}{c}\text { Durchfälle, Fieber, Milzschwel- } \\
\text { lung, klinisch Paratyphus }\end{array}$ & $"$ & & $"$ & & - & - & - & - & - & - \\
\hline 104 & Urin von Fall 103 & & $"$ & $"$ & & - & - & - & - & - & $\leftarrow$ \\
\hline 105 & $\begin{array}{l}14 \text { Tage krank, Kopfschmerz, } \\
\text { hohes Fieber, Durchfall, Milz- } \\
\text { schwêllung }\end{array}$ & $"$ & & $"$ & & - & - & - & - & - & - \\
\hline 106 & Urin von Fall 105 & & $\eta$ & $"$ & & - & 一 & - & - & - & - \\
\hline
\end{tabular}

1 Paratyphus +. 
(SchluB.)

\begin{tabular}{|c|c|c|c|c|c|c|c|c|c|c|c|}
\hline 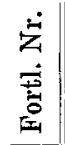 & Klinische Angaben & 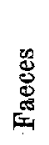 & 菅 & 蒫 & 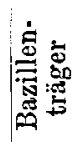 & 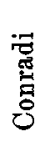 & 害 & 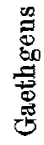 & 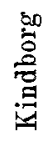 & $\underset{:}{\stackrel{9}{9}}$ & 兽 \\
\hline 107 & Typhusverdacht & $"$ & & $n$ & & - & - & - & - & - & - \\
\hline 108 & $\begin{array}{l}\text { Typhus- oder Paratyphusver- } \\
\text { dacht, Roseolen, Milztumor, } \\
\text { Diazo positiv, 12 Tage krank }\end{array}$ & $"$ & & " & & - & + & + & + & 一 & + \\
\hline 109 & Urin von Fall 108 & & " & $"$ & & + & - & - & + & - & + \\
\hline 110 & $\begin{array}{l}4 \text { Wochen krank, Durchfälle, } \\
\text { Darmblutungen, Milztumor }\end{array}$ & $"$ & & $"$ & & - & - & - & - & - & - \\
\hline 111 & $\begin{array}{l}\text { Durehfälle, Ruseolen, Milz- } \\
\text { schwellung, } 14 \text { Tage krank }\end{array}$ & $"$ & & 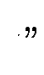 & & - & - & - & + & 一 & + \\
\hline 112 & $\begin{array}{c}\text { Klin. Typhus, } 12 \text { Tage krank, } \\
\text { hohes Fieber, Milzschwellung, } \\
\text { Roseolen }\end{array}$ & $"$ & & $"$ & & - & 一 & - & + & - & - \\
\hline 113 & Urin ron Fall 112 & & $"$ & $"$ & & - & - & - & - & - & - \\
\hline 114 & $\begin{array}{l}\text { Klin. Typhusverdacht, } 8 \text { bis } \\
\text { 10 Tage krank, Fieber, mit } \\
\text { mehreren in der Prov.-Heil- } \\
\text { anstalt erkrankt }\end{array}$ & $"$ & & $"$ & & - & 一 & - & - & - & 一 \\
\hline 115 & Urin von Fall 114 & & $n$ & $"$ & & - & - & - & - & 一 & - \\
\hline
\end{tabular}

Nach Erledigung der Vorversuche ging ich zu den Untersuchungen an echtem Typhusmaterial über, die sich auf vorstehende 115 Fälle erstreckten. Nach der Herkunft des Materials verteilen sich diese Untersuchungen folgendermaßen:

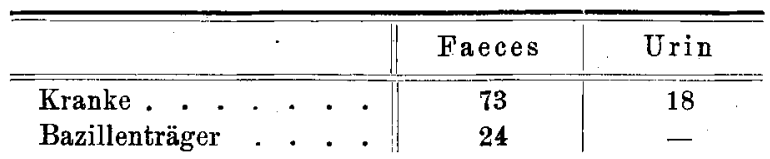

Unter dem beim hiesigen Institut täglich eingesandten, auf Typhusbazillen zu untersuchenden Material wählte ich möglichst solches aus, dem auf Typhuserkrankung hinweisende klinische Angaben beigefügt waren.

Bei den Resultaten berücksichtigte ich nicht das quantitative Wachstum der Typhusbazillen, sondern notierte, ob positiver oder negativer Befund vorlag. Von diesen 115 Untersuchungen waren:

1. Positiv überhaupt 51 Fälle, d.s. 44.4 Proz., negativ 64, d. s. 56.6 Proz.

2. Faeces $47 \mathrm{mal}$ positiv, d. s. 48.0 Proz., 50 mal negativ, d. s. 52.0 Proz. Urin $4, ", 22.0,, 14, " 78 \cdot 0$, . 3. Typhusbazillenbefund 47 mal positiv, Paratyphusbazillen 4 mal positiv. , 60, negativ, 4, negativ. 
4. Von 73 Faeces, von Kranken stammend, 29 positiv,

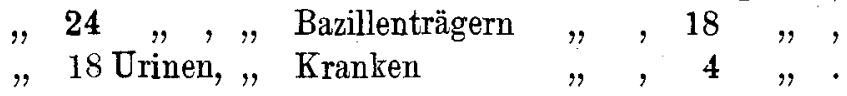

Entsprechend den einzelnen Nährböden verteilt sich das Resultat. folgendermaßen:

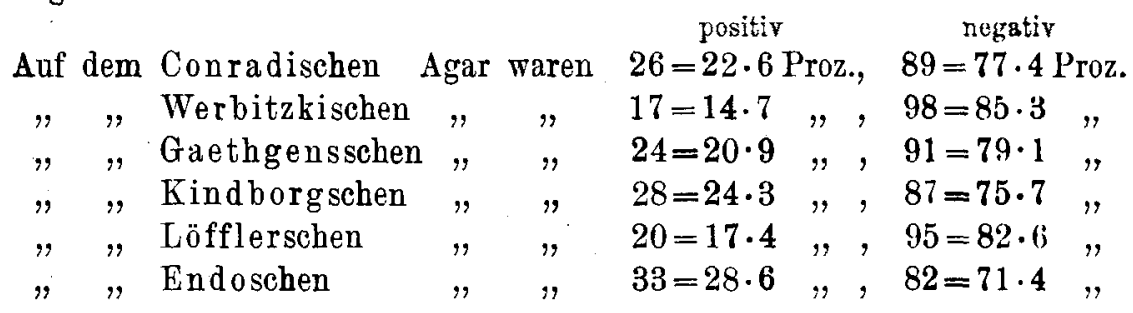

. In den Fällen, wo die übrigen Nährböden versagten, war der

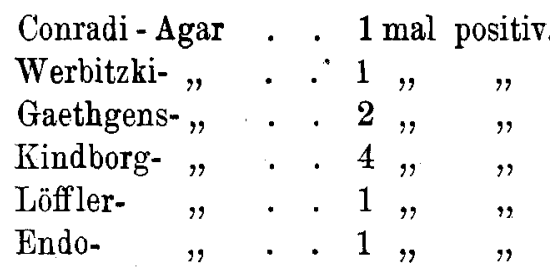

Es versagten in den Untersuchungen bei Fällen, die mit einem oder mehreren der Nährböden positiv waren, der

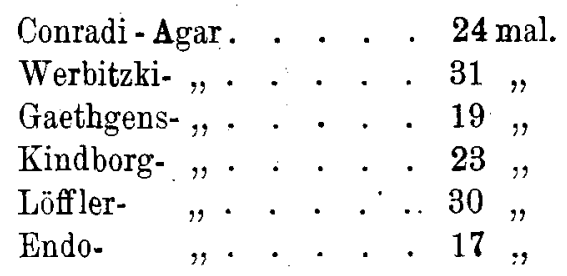

Das Wachstum der Bakterienkolonien war, wie ich schon bei der Schilderung der Vorversuche kurz erwähnte, bis auf das Fehlen der körnigen Struktur der Typhuskolonien auf dem Conradiagar im allgemeinen so, wie es von den Autoren angegeben wird. Wie schon in den Vorversuchen, zeigte sich auch in den Untersuchungen mit echtem Typhusmaterial, daB auf dem Conradischen und Werbitzkischen Agar reichlich Bact. coli gedieh. Auf ersterem Nährboden erwies sich die Unterscheidung zwischen Bact. typhi und Bact. coli besonders bei etwa 18 bis 20 stündiger Bebrütung als äuBerst schwierig, ja fast unmöglich. Die Kolonien der Typhus- und Colibakterien waren hell, durchsichtig, von StecknadelkopfgröBe und voneinander nicht zu unterscheiden. Nur in ganz vereinzelten Fällen waren nach dieser Bebrütungsdauer die Typhuskolonien größer als 
die des Bact. coli und von diesen differenzierbar. Es zeigte sich bald, dab die Conradische Platte ein längeres Verweilen, etwa 30 bis 36 Stunden, im Brutschrank bei $37^{\circ}$ nötig hatte, ehe die Differenzierung sich ermöglichen lieB.

Nach dieser Zeit erschienen in den Untersuchungen mit echten Typhusdejehten wie in den Vorversuchen die Typhuskolonien als groBe, zuweilen riesenhafte, helle, etwas durchsichtige Kolonien, die rundlich, flach, in der Mitte dicker als am Rande waren und sich gut unterscheiden ließen von den dann allerdings ebenfalls beträchtlich größer gewordenen, aber vollständig undurchsichtigen, metallisch glänzenden Kolonien des Bact. coli. Die körnige Struktur der Typhuskolonien, auf die von Conradi und anderen Untersuchern groBer Wert gelegt wird, da sie das Fehlen eines Farbenunterschiedes zu ersetzen imstande wäre, habe ich, allerdings bei längerer Bebrütungsdauer, gern entbehren können. Zuwèilen schwemmte ich die Conradischen Platten nach dem Vorgehen von Gaethgens und Brückner (25) schon nach 18 bis 20 stündiger Bebrütungsdauer ab und säte von der Abschwemmung auf Endoplatten aus. Gaethgens und Brückner hatten mit dieser Modifikation des Verfahrens häufig noch ein positives Resultat, wenn die Originalplatte negativ gewesen war. Ihr Gesamtresultat betrug 41 Prozent positive Fälle auf der Conradischen Platte ohne Abschwemmung und stieg bei Abschwemmung auf 59 Prozent. Bact. coli zeigte in ihren Versuchen ein wechselndes Verhalten. Ich muB bezüglich der Abschwemmungsmethode des Conradiagars ebenfalls günstig berichten; denn von 50 Abschwemmungen 18 bis 20 Stunden bebrüteter Platten waren 10 (20 Prozent) positiv. Ich glaube aber, daB die abgeschwemmten Platten bei längerem Verweilen im Brutschrank ebenfalls positiv geworden wären, weil dann die rorher übersehenen Typhuskolonien genügend charakteristisch geworden nnd erkannt worden wären. Letzterem Verfahren möchte ich daher vor dem umständlichen und etwas kostspieligeren Abschwemmungsverfahren mehr das Wort reden, zumal kein Zeitgewinn bei der Abschwemmung erlangt wird. - Zuweilen beobachtete ich auf der Conradischen Platte eine ausgesprochene Hemmung der Colikeime, aber eben keineswegs immer, und der hier schon erwähnten Ansicht von der verschiedenen Resistenzfähigkeit der Keime gegen Grünstoffe $(12,13,14,22)$ kann ich mich nach diesen Versuchen an echtem Untersuchungsmaterial nur ansehließen. Bact. paratyphi wuchs in meinen. Untersuchungen wie Bact. typhi, nur noch üppiger und war daher leicht von Bact. coli zu unterscheiden. Unter 8 auf Bact. paratyphi zu untersuchenden Dejekten waren auf Conradis Agar 2 positiv. Die von mir erzielten 22.6 Prozent positiven Fälle sind ein nur etwa halb so günstiges Resultat wie das ron Kathe und Blasius (26), die bei ihren 
auf 53 echte Typhusdejekte sich erstreckenden Untersuchungen 45 Prozent positive Fälle erzielten. Kathe und Blasius konnten ebenfalls keine vollständige Hemmung des Bact. coli konstatieren., Noch weniger stimmen meine Resultate mit denen Kypke-Burchardis (27) überein, der besonders die quantitativen Verhältnisse berücksichtigte, aber keine natürlichen Typhusstühle, sondern Reinkulturen in seinen Versuchen verwendete. Er erzielte auf einer Conradischen Platte mit gemischter Aussaat 63 Prozent Ernte an Typhusbazillen und nur 7 Prozent Ernte an Colibakterien. Demgemäß stimmt er der Behauptung Conradis von der starken Wachstumsbeeinträchtigung des Bact. coli auf Conradiagar durchaus zu. In weiterem Gegensatz zu meinen Beobachtungen fand Kyphe-Burchardi, daB die Kolonien des Bact. typhi sich auf diesem Nährboden mach 18 bis 20 stündiger Bebrütung viel zarter und feiner ausnehmen als auf Drigalski- oder gewöhnlichem Agar. Wie ich schon oben schriob, waren die Typhuskolonien um diese Zeit etwa von StecknadelkopfgröBe. Nur vom Bact. paratyphi erwähnt Kypke-Burchardi, daB dieses üppig wuchere. Wie von Kypke-Burchardi so wird auch vom Gelsenkirchener Institut im Jahresbericht von 1908 (28) die mangelhafte Differenzierung der'Typhuskolonien auf Conradischem Agar auf Grund schon damals mit diesem Nährboden ausgeführter Versuche als ungünstiger Umstand herrorgehoben. Gleichfalls meinem Resultate auf Conradis Agar überlegen ist das Megeles (29), der Faecesproben ron Bazillenträgern untersuchte und dabei auf der Conradischen Platte 66.6 Prozent positive Resultate erzielte. Cu rimm(30), der 25 Stuhlproben von Kranken und Bazillenträgern untersuchte, erzielte dabei eine Ernte von 56 Prozent positiven Fällen. Vom Bact. coli schreibt er, da $B$ dieses kein durchgehend gleichsinniges Verhalten zeige, d. h. weder regelmäBig Hemmung noch regelmäßíg Wachstum des Bact. coli auf dem Conradiagar stattfinde. Dieser Ansicht über das Wachstum des Bact. coli auf diesem Nährboden möchte ich nach meinen Untersuchungen am meisten beistimmen. Auch Werbitzki (31) äuBert sich in diesem Sinne, wenn er schreibt, daB das Bact. coli auf Conradis Brillantgrünagar doch noch in nicht unbeträchtlichen Mengen wächst. - Wesentlich anders als die bisher geschilderten Erfolge der verschiedenen Untersucher sind die Schumachers (32) mit dem Conradischen Agar, der auch Stühle der Praxis untersuchte und dabei 10.8 Prozent positive fand. Schumacher fand ebenfalls, daß keineswegs Bact. coli völlig gehemmt werde, dagegen Proteusund Alkaligenesarten sugar noch üppiger wuchsen als Bact. typhi und Bact. paratyphi, was auch von Kypke-Burchardi schon hervorgehoben wird. Ich habe nur einmal Bact. faecal. alcaligen. in meinen Untersuchungen beobachten können. Zu Schröders (33) Ansicht, daB der Conradische Brillantgrünagar wie jeder andere Agar das Wachstum der 
Typhusbakterien hemmt, möchte ich keine Stellung nehmen, da ich das quantitative Wachstum weniger berücksichtigte. Schröder ließ, da 35 mittels Vorkultur auf Conradis Agar untersuchte echte Typhusfaeces negativ waren, diese Methode fallen. - Kurz möchte ich noch die Resultate einiger anderer Nachprüfer des Conradischen Agars streifen. Fischer (34), der 100 sicher Typhusbazillen enthaltende Faecesproben untersuchte, erzielte mit Conradis Agar 48 Prozent, dagegen mit Endo 63 Prozent und mit dem Lentz-Tietz-Verfahren 76 Prozent positive Resultate. Prigge (35) hatte ein besseres Resultat, hebt aber das Fehlen eines Farbenunterschiedes zwischen Typhus- und anderen Kolonien als erschwerend hervor. Rimpau (36) erzielte in einzelnen Fällen allein mit Conradis Agar positive Resultate, in anderen Fällen dagegen versagte er. Auf Grund meiner Untersuchungen" glaube ich den Conradiagar für einen in der bakteriologischen Typhusdiagnostik gut brauchbaren Agar halten zu müssen. Seine Herstellung ist nicht zu schwierig, sein Preis nicht zu teuer, die Diagnostik der Typhuskolonien nach den oben genannten Merkmalen verhältnismäßig leicht. Die Anlegung einer großen Platte, mit 2 bis 3 Ösen verdünnten Stuhles beimpft, fand ich genügend; nur anfangs verwendete ich zwei Platten. Mit dem Endoschen Nährboden, glaube ich, kann der Con radische aber doch nicht konkurrieren, denn bei letzterem ist längere Zeit zur Stellung der Diagnose nötig, und auf dem Endoagar haben die Typhuskolonien infolge ihres Farbenunterschiedes von den Kolonien des Bact. coli doch mehr Charakteristisches an sich. Die Zahl der positiven Fälle auf Endoschem Agar war in meinen Untersuchungen um 7 gröBer, als die auf Conradis.

Mit dem Werbitzkischen Nährboden, von dem ich anfangs 'zwei, später eine große Platte anlegte, erzielte ich $17 \mathrm{mal}$ ein positives Resultat, d. i. ein um 10 geringeres als das mit Endos Agar erzielte. Bact. paratyphi war bei den 8 Paratyphusuntersuchungen zweimal positiv auf diesem Agar. Als Aussaatmenge fand ich, wie bei Conradis Agar, 2 bis 3 Platinösen für eine große Platte genügend. Charakteristische Merkmale der Typhuskolonien, auf deren Mangel schon Werbitzki hinweist, vermochte auch ich nicht zu entdecken. Die Kolonien des Bact. typhi waren nach 18 Stunden etwa von Stecknadelkopfgröße. Die Kolonien des Bact. coli, die in den Vorversuchen sowohl wie in den Versuchen mit echten Faeces reichlich wuchsen, waren um diese Zeit etwa von derselben Größe wie die des Bact. typhi, zuweilen etwas größer, aber lange nicht so hell und durchsichtig wie diese, vielmehr war der'Farbenton etwas milchig trübe. Durch diesen Farbenunterschied gelang es mir daher in der Mehrzahl der Fälle, die Typhusbakterienkolonien direkt auf der Originalplatte zu erkennen, wenn auch die Erkennung zuweilen schwierig und infolge vieler 
anzustechender, verdächtiger Kolonien etwas mühselig war. Leider fehlte dieser Farbenunterschied zwischen Typhus- und Colikolonien zuweilen ganz, so daß ich in einer großen Anzahl von Fällen nach Werbitzkis Vorschlag abschwemmte und auf Endosche Platten aussäte. Von 53 abgeschwemmten Platten waren 6 positiv. Das von mir mit Werbitzkiagar crzielte Resultat steht im Gegensatz zu dem von Gaethgens und Brückner (25), die in 100 Untersuchungen mit Werbitzkiagar 53 Prozent, mit kndoagar nur 56 Prozent positive Resultate erzielten. Trotzdem geht ihr Urteil duhin, dab dem Werbitzkiagar nur geringe Bedeutung zukommt, da die lauer der Untersuchung infolge der Abschwemmung eine sehr lange und die colihemmende Wirkung eine geringe wäre. Schröder (33) dagegen, der Versuche mit 334 echten Typhusfaeces ausführte, schreibt, dab Buct. coli fast gar nicht auf Werbitzkiagar wächst, Typhusbakterien würdon allerdings nicht unbeträchtlich gehindert. In diesen Untersuchungen waren positiv durch direktes Endoverfahren $21=6.61$ Prozent und durch lindoChinagrünverfahren Werbitzkis $47=11.07$ Prozent. Trotzdem ioh mit dem Werbitzkischen Agar kein allzu ungünstiges Resultat erzielte (14.7 Prozent), glaube ich doch, dab seiner Einführung in die l'ruxis Bedenken entgegenstehen. Die Erkennung auf den Originalplatten ist, schwierig, zuweilen unmöglich. Das umständliche Abschwemmungsverfiuhren förderte in meinen Untersuchungen nur wenig positive Resultate. Ein Bedürfnis nach einem neuen Vorkulturverfahren besteht auch wohl nur wenig, da sich das Lentz-Tietz-Verfahren recht gut bewährt hut. S(olange es nicht gelingt, den Werbitzkischen Nährboden dahin : ibzuiudern. daB eine direkte Erkennung der Typhuskolonien auf den Originalplatten in jedem Falle möglich ist, kann dieser Nährboden kaum $\Lambda$ nspruch auf Verwendung in der bakteriologischen Typhusdiagnostik machen.

Während auf Conrad ischem und Werbitzkischem Agar Bact. coli recht reichlich gedieh, wurde auf dem Gaethgenssehen Agar in allen w'ïllen eine vollständige Hemmung desselben erreicht. Dieser Umstund gestattet eine große Menge des Untersuchungsmateriales auszusäen. Ich verwendete meist 0.4 bis $\mathbf{0 . 5}{ }^{\mathrm{com}}$ verdünnten Stuhles als Aussaatmengre. Das Wachstum der Typhuskolonien gestaltete sich so, wie ich bei der Schilderung der Vorversuche kurz erwähnte. Die Verlangsamung des Wachstums war eine derartige, daß nach 30 stündigem Verweilen der Platten im Brutschrank bei $37^{\circ}$ die Kolonien des Bact. typhi die GrïBe einer Stecknadelspitze hatten, so daB die Diagnosenstellung keinesfalls möglich war. Erst in den nächsten 8 bis 10 Stunden wuchsen die Typhuskolonien rascher, so daß sie nach 38 stündiger Bebrütung etwa von der Größe eines Stecknadelkopfes waren. Die Kolonien hatten, wie der Nährboden selber einen schwach rosaroten Farbenton, waren fast undurchsichtig und am Rande 
gefiedert. Die Angaben von Gaethgens und Brückner (25), daB die Typhusbakterien zu Fäden auswachsen und die Agglutination das Bild wirr verschlungener Fäden bietet, $m u ß$ ich bestätigen. Das Bild dieser Agglutination war charakteristisch genug, um die betreffende angestochene Kolonie als Typhuskolonie zu erkennen. In allen Fällen von Paratyphus versagte dieser Nährboden leider. Von Begleitbakterien wuchsen auf den Gaethgensschen Platten nur noch Strepto- und Staphylokokkenarten, die aber nach 38 Stunden noch so klein waren, daß eine Verwechselung mit den um diese Zeit ausgewachsenen und charakteristischen Typhuskolonien nicht möglich war. Gaethgens und Brückner (25) erzielten mit diesem Nährboden 58 Prozent, mit dem einfachen Endoagar nur 50 Prozent positive Resultate. Um dieselbe Differenz, nämlich 8 Prozent, war in meinen Untersuchungen der Gaethgenssche Agar dem Endoschen an positiven Resultaten unterlegen. Die Isolierung der Typhuskolonien infolge der vollkommenen Hemmung der Begleitbakterien war auf diesem Agar so gut, daß die Stellung der Diagnose sehr leicht war. Die Wachstumsverlangsamung der Typhuskolonien aber und damit die Verzögerung der Diagnose sowie die numerische Unterlegenheit der positiven Resultate dieses Nährbodens gegenüber den auf Endos Agar erzielten lassen den Gaethgensschen Agar dem Endoschen nicht gleichwertig erscheinen; trotzdem halte ich seine Verwendung in der Typhusuntersuchung der Untersuchungsämter wohl für möglich.

Der Kind borg sche Agar lieferte das günstigste Resultat der von mir geprüften neueren Nährböden und wurde nur von Endos Agar übertroffen. Wie aus der obigen Tabelle ersichtlich, ergaben sich 24.3 Prozent positive Resultate auf Kindborgs Agar. Die Aufhellung des Nährbodens in der Umgebung der Typhuskolonien war zuweilen stärker oder schwächer, aber immer erkennbar, nur in wenigen Fällen war sie undeutlich oder blieb aus. Eine Hemmung des Bact. coli fand aber keineswegs in dem MaBe statt, wie ich es nach Kindborgs Schilderung erwartete, und wie ich es bei den Vorversuchen beobachtet hatte. Vielmehr war das Wachstum zuweilen so dicht, daB etwaige Typhuskolonien infolge der durch viele Colikolonien bedingten Säurebildung ihre Farbenreaktion nicht entwickeln konnten. Ich rate daher, bei Nachprüfung des Kindborgschen Agars eine bis drei grobe Platten zu verwenden. Als Aussaatmenge verwendete ich 3 bis 5 Platinösen verdünnten Stuhles. Auf der zweiten oder dritten Platte waren die Typhuskolonien dann stets genügend isoliert, so $\mathrm{daB}$ die erwartete Farbenreaktion eintrat. Ein Übersehen etwaiger Typhuskolonien war auf diesem Agar unmöglich. Kathe und Blasius (26), die übrigens nur eine große und drei kleine Platten bei der Prüfung dieses Nährbodens verwendeten, hatten nur 6 Prozent positive Erfolge mit 
dem Kindborgschen Agar. Sie führten dieses ungünstige Resultat auf das verwendete Malachitgrünpräparat zurück, das sich ihnen auch beim Lentz-Tietz-Verfahren nicht bewährte. Im allgemeinen beobachteten sie eine starke Wachstumshemmung auf diesem Agar. Diese Beobachtung machte ich zwar auch, und es dürfte sich empfehlen, das zur Verwendung kommende Malachitgrünpräparat auf seine Brauchbarkeit hin zu prüfen. So konnte ich einmal einen Agar nicht gebrauchen, bei dem ich ein neu bezogenes Malachitgrünpräparat verwendete, das aber ebenfalls als „Malachitgrün Höchst, Fabrikmarke I a“ von Dr. Grübler-Leipzig bezogen war. Auf diesem Agar war überhaupt kein Wachstum zu erzielen. Erst als ich ein anderes Malachitgrünpräparat verwendete, das aber gleichfalls unter demselben Namen von derselben Firma bezogen war, erzielte ich wieder Wachstum. Vielleicht sind die Malachitgrünpräparate in ihrer chemischen Zusammensetzung doch noch schwankend und besitzen daher zuweilen schädigenden EinfluB auf die Bakterien. Mehrere Male beobachtete ich aber auch Kolonien auf Kindborgs Agar, die die für Typhuskolonien auf diesem Nährboden charakteristische Farbenreaktion zeigten, und die sich dann bei weiterer Identifizierung nicht als Typhuskolonien erwiesen. Mit Paratyphusbakterien, allerdings bei Versuchen mit Reinkultur, hatten Gaethgens und Brückner (25) so gute Erfolge, daB sie deshalb Kind borge Agar einen Elektivnährboden für diese Bakterienart nannten. Ich kann diesem Urteil nicht zustimmen, denn von den 8 Paratyphusfällen in meinen Untersuchungen versagte der Kind borgsche Agar in 6 Fällen. Grimms (30) Urteil über den Kindborgschen Agar ist kein günstiges. Grimm sagt, die von den Autoren geforderte Farbenreaktion trete nur ein bei Stühlen, die zahlreiche Typhuskeime enthielten, bei Übersüuerung des Nährbodens durch Begleitbakterien aber trete die;von Kindborgs Agar erwartete biologische Funktion der Typhusbazillen, Nitritbildung und dadurch Entfärbung des Agars, nicht ein. Diese Möglichkeit suchte ich eben durch Anlegung mehrerer grober Platten zu umgehen. Grimm (30) benutzte nur Faeces von Fällen, die durch klinische Symptome eine gewisse Garantie für die Auffindung von Typhusbakterien boten. Er erzielte 6 positive Fälle, d. h. 24 Prozent in seinen Untersuchungen. Unter den 28 positiven. Fällen (24 Prozent) in meinen Untersuchungen war Kindborgs Agar viermal positiv in Fällen, in denen alle anderen Nährböden versagten. Die Herstellung dieses Agars ist einfach, der Preis mäBig. Auch bei Verwendung dreier großer Platten würden sich die Kosten der Typhusuntersuchung eines Untersuchungsamtes nicht zu teuer stellen. Ein Umstand aber, der sich der Einführung des Kindborgschen Agars in den GroBbetrieb einer bakteriologischen Untersuchungsanstalt entgegenstellen dürfte, auf den auch Grimm schon hinweist, ist die außerordent- 
lich rasche Ermüdung des Auges des Untersuchenden durch den intensiv roten Farbenton des Agars. Die Augen schmerzten geradezu bei längerem Hinsehen auf diesen Nährboden, und der Untersucher in einem Untersuchungsamte, der täglich Hunderte von Platten durchzusehen hat, könnte wohl schwerlich mit diesem Nährboden dauernd arbeiten.

Der letzte der von mir nachgeprüften neueren Nährböden, Löfflers Reinblauagar, war derjenige, der wie Gaethgen s' Agar gute Hemmung der Begleitbakterien zeigte. Ich legte immer eine Plattenserie $z \mathfrak{u}$ drei Platten von einem Agar an, dem ich pro $100^{\mathrm{cem}}$ Agar $4{ }^{\mathrm{em}}$ einer 0.2 prozentigen Malachitgrünlösung zugesetzt hatte. Ijöffler empfahl, eine weitere Serie anzulegen von einer Agarsorte, der pro $100^{\mathrm{cm}}$ Agar nur $3^{\mathrm{cm}}$ der 0.2 prozentigen Malachitgrünlösung zugesetzt waren. Die Anlegung dieser zwei Serien verschiedener Farbstoffkonzentration sollte offenbar, wie auch Schröder (33) schreibt, dem schwankenden Keimgehalt der Faeces Rechnung tragen. Um den bei meinen Versuchen etwas ausgedehnten Materialverbrauch niçht noch zu vergrößern, lieB ich diese zweite Serie fort. Fine Verschlechterung meiner Resultate befürchtete ich nicht, denn Sch rö der (33) war in seinen Untersuchungen der Nachweis der Typhuskolonien auf jeder der beiden Reinblauserien mit verschiedener Farbstoffkonzentration gelungen. Ich fand in meinen Untersuchungen den Wuchs der Typhuskolonien nicht ganz so, wie es Löffler beschreibt. Sie waren flach, pyramidal, aber keineswegs immer tiefblau, vielmehr hellblau oder hell und durchsichtig. Einen Stahlglanz der Typhuskolonien konnte ich nicht konstatieren. Die Kolonien des Bact. coli hatten wie die ganze Platte nach 18 bis 24 stündiger Bebrütung einen schwach rötlichen Farbenton angenommen, und da die Colibakterien so wenig wuchsen, so waren die Typhuskolonien genïgend isoliert und ihre Erkennung nicht schwer. Der Zahl nach lieferte Löfflers Agar ein viel geringeres Resultat (17.4 Prozent) als Endos (28.6 Prozent), während Schröder in seinen Untersuchungen mit ersterem 19 Prozent, mit letzterem nur 16.6 Prozent positive Resultate erzielte. Baet. paratyphi war auf Löfflers Agar zweimal positiv in meinen Untersuchungen. Eine Beeinträchtigung der Agglutinierbarkeit der Typhusbakterien, von der Schröder (33) schreibt, konnte ich nicht konstatieren. Erwähnen möchte ich noch, daB der Agar nach Zusatz der Farbstoffe kein längeres Aufbewahren verträgt, weil, wie. ich schon sagte, sich leicht Niederschläge bilden, die nachher in dem auf Platten ausgegossenen Agar als flockige, blauschwarze Trübungen erscheinen. Den nicht allzu hohen in meinen Untersuchungen erzielten positiven Resultaten nach zu urteilen, scheint sich die Wachstumshemmung des Reinblauagars nicht nur auf die Begleitbakterien, sondern auch auf die Typhusbakterien zu erstrecken. Da ich aber keine genaue Keimzahl- 
bestimmung rornahm, so möchte ich in dieser Beziehung über den Nährboden kein Urteil abgeben. Die Erkennung der 'l'yphuskolonien auf diesem Agar ist nicht schwierig; leider lieferte er in meinen Untersuchungen nur eine geringe Anzahl von positiven Fällen, trotzdem dürften aber weitere Versuche mit dem Löfflerschen Agar geboten sein.

Der Endosche Nährboden, den ich als exprobtes Nährmedium nur vergleichsweise verwendete, bewährte sich am besten. Auf ihm erzielte ich die Höchstzahl der positiven Resultate mit $33=28.6$ Prozent. Allerdings versagte Endos Agar in 18 Fällen, in denen ein oder mehrere andere Nährböden positiv waren, trotzdem aber hatte ich auf ihm die meisten positiven Fälle. Für Paratyphusuntersuchung vorsugtu Eudos Agar zweimal. Die Diagnose gelang stets in der kürzesten /heit, 15 bis 20 Stunden, und das Wachstum der Typhuskolonien war stets genilgend charakteristisch. Eine nähere Schilderung des letzteren kaun ich, weil genügend bekannt, unterlassen. Keiner der geprüften neueren Nährbieden vermochte den erprobten Endoschen zu übertreffen. Von den von mir nachgeprüften neueren Nährböden scheint mir Conradis Brilluntgrüungar und Gaethgens' Koffein-Endofuchsinagar zum bakteriologisohen Nachweis von Typhusbazillen gut geeignet zu sein. Wo es sich nicht um Mnssenuntersuchungen handelt, die das Auge des Untersuchers zu rasch ermilden bei Verwendung des intensiv roten Kindborgschen Agars, ist auch dieser Nährboden mit sehr gutem Erfolge zu verwenden. Auch Lüfflars Ruinblauagar könnte vielleicht erfolgreich in die Technik der Typhusuntersuchung eingeführt werden. Werbitzkis Chinagrünagar dagegen bedarf noch weiterer Modifikation, um in der Praxis Verwendung linden zu können. Ein Idealnährboden aber ist keiner der nachgeprüften; denn die von einem solchen zu fordernden Bedingungen, Ausschaltung der Konkurrenzbakterien, Begünstigung und charakteristische Markierung der Typhuskolonien in kürzester Bebrütungsdauer, erfüllt keiner derselben. 


\section{Literatur-Verzeichnis.}

1. Conradi, Ein Verfalıren zum Nachweis spärlicher Typhusbazillen. Münch. med. Wochenschrift. 1908. S. 1523.

2. Werbitzki, Ein neuer Nährboden zum Nachweis von Typhusbazillen in Faeces. Archiv f: Hygiene. Bd. LXIX. S. 191.

3. Walter Gaethgens, Über die Erhöhung der Leistungsfähigkeit des Endoschen Fuchsinagars durch den Zusatz von Koffein. Centralblatt' $f$. Bakteriologie usw. Abt. I. Origin. Bd. XXXIX.

4. E. u. A. Kindborg, Eine neue Farbenreaktion zur Erkennung der Typhusbazillen u. verwandter Arten im Plattenansstrich. Ebenda. Abt. I. Orig. Bd. XLVI. S. 554 .

5. F. Löffler, Ein neues Verfahren zum Nachweis u. zur Differentialdiagnose der Typhusbakterien mittels Malachitgrün-Safranin-Reinblaunährböden. Deutsche med. Wochenschrift. 1909. Nr. 30.

6. Endo, Über ein Verfahren zum Nachweis der Typhusbazillen. Centralblatt für Bakteriologie usw. Abt. I. Orig. Bd. XXXV. S. 109.

7. Marschall, Die Bedeutung des Endoschen Nährbodens für die bakteriol. Typhusdiagnose. Ebenda. Abt. I. Origin. Bd. XXXVIII. S. 347.

8. Petkowitsch, Ein Beitrag zur Frage des diagnostischen Wertes einiger Nährböden für die Typhusbakterien. Ebenda. Abt. I. Origin. Bd. XXXVI. S. 304.

9. Simon, Erfahrungen mit dem von Drigalski-Conradischen Milehzuckeragar bei der Typhusbekämpfung. Klin. Jahrbuch. 1907. Bd. XVII.

10. Conradi, Über ein Verfahren zum Nachweis der Typhusbazillen. Diese Zeitschrift. 1901. Bd. XXXIX. S. 289.

11. Lentz und Tietz, Eine Anreicherungsmethode für Typhus- u. Paratyphus. bazillen. Münchener med. Wochenschrift. 1903. Nr. 44.

12. Klinger, Über Typhusbazillenträger. Arbeiten aus dem Kaiserl. Gesundheitsamt. Bd. XXIV.

13. Doebert, Wachstum von Typhus- und Coli-Reinkultaren auf verschiedenen Malachitgrün-Nährböden. Archiv für Hygiene Bd. LIX. S. 370.

14. Novack, Über die Grenzen der Verwendbarkeit des Malachitgrünagars zum Nachweis der Typhusbazillen im Stuhl. Ebenda. Bd. LIV. - Bd. LXXX. S. 374.

15. Roth, Versuche über die Einwirkung des Koffeins auf das Bact. typhi und coli. Hygien. Rundschau. 1903. Bd. XIII. - Archiv für Hygiene. Bd. IL.

16. Löffler, Zum Nachweis und zur Differentialdiagnose der Typhusbazillen mittels der Malachitgrünnährböden. Deutsche med. Wochenschrift. 1903. Vereinsbeilage Nr. 36. - Ebenda. 1906. Nr. 8. 
17. Ficker u. Hoffmann, Über neuere Methoden des Nachweises von Typhusbazillen. Hygien. Rundschau. 1904. Bd. XIV. - Archiv für Hygiene. 1904.

18. Klinger, Über neuere Methoden zum Nachweis der Typhusbazillen in den Darmentleerungen. Dissertation. Straßburg 1904.

19. Reischauer, Über den Nachweis von Typhusbazillen in den Darmentleerungen mit Verwendung der neueren Untersuchungsmethoden. Centralblatt $f$. Bakteriologie. Abt. I. Orign. Bd. IL. S. 116.

20. Massen, Die Zersetzung der Nitrate und Nitrite durch die Bakterien. Arbeiten aus dem Kaiserl. Gesundheitsamt. Bd. XVIII.

21. Lubenau, Das Koffeinanreicherungsverfahren zum Typhusnachweis im Stuhl. Archiv für Hygiene. Bd. LXI. S. 232.

22. N eumann, Über die Untersuchung: von Typhusstühlen mittels Malachitgrünnährböden. Ebenda. Bd. LXIX.

23. Jorns, Über die Brauchbarkeit des Malachitgrünnähragars zum Nachweis von Typhusbazillen. Hygien. Rundschau. 1904. Nr.15. S. 713.

24. Peabody und Pratt, Über den Wert von Malachitgrünnährböden zur Differenziernng von Typhus- nnd Colibazillen. Centralblatt für Bakteriologie usw. Abt. I. Orig. Bd. XLV. S. 550.

25. Gaethgens und Brückner, Vergleichende Untersuchungen über einige neuere Typhusnährböden und Erfahrungen über den Wert der Agglutination. Blut. kultur und Stuhlzüchtung für die Diagnose des Abdominaltyphus. Ebenda. IBl. IJIII. S. 559.

26. Kathe und Blasius, Vergleichende Untersuchungen über die Leistangsfähigkeit älterer und neuerer Typhusnährböden. Ebenda. Orig. Bd. IJII.

27. Kypke-Burchardi, Über die Branchbarkeit des Conradischen Brillantgrün-Typhusnährbodens. Hygien. Rundschau. 1908. Nr. 21.

28. Jahresbericht des Inst. f. Hyg. u. Bakt. zu Gelsenkirchen. 1908.

29. Megele, Erfahrungen mit dem neuen Malachitgrünagar Padlewskys zum Nachweis von Bazillen der Typhusgruppe. Centralblatt f. Bakteriologie usw. 1909. Abt. I. Orig. Bd. LII. S. 616-619.

30. Grimm, Über den praktischen Wert einiger neuerer Typhusnälırböden. Hygien. Rundschau. 1909. Bd. XIX.

31. Werbitzki, Untersuchungen über den diagnostischen Wert einiger Nährböden für den Nachweis von Typhusbazillen in Faeces. Archiv f. Hygiene. Bd. IXXIX.

32. Schumacher, Vergleichender Typhusnachweis mittels des kombinierten Endo-Malachitgrünverfahrens und des Conradischen Brillantgrünpikrinsäureagars. Klin. Jahrbuch. 1909. Bd. XXI. S. 209-218.

33. Schröder, Beiträge zum Nachweis von Typhusbazillen in Stühlen mittels Brillantgrün-, Chinagrün- und Reinblauagar. Ebenda. 1911.

34. Fis cher, Konferenz der Leiter der Typhusuntersuchungsanstalten am 23. $X$. 1909 in Landau i. Pf.

35. Prigge, Ebenda.

36. Rimpau, Vierteljahresbericht der bakteriolog. Anstalt Hagenau i. E. für die Zeit vom 1. April bis 30. Juni 1909. 